\title{
Comparison of calves' rearing parameters in two different housing systems: indoor versus outdoor hutches
}

\author{
Agata Wójcik, Teresa Nałęcz-Tarwacka and Marcin Gołębiewski \\ Warsaw University of Life Sciences, Warsaw, Poland
}

\begin{abstract}
The main aim of the study was to compare the rearing effect of calves kept outdoor in individual hutches and indoor in group pens. During the experiments, the following measurements were carried out: body weight, daily gains, feed intake, morbidity and mortality. The study was conducted on 90 calves from 5th to 90th day of age; all calves were fed the same feed and according to the same schedule. Results revealed that during the first month, the calves from both groups achieved the same daily gains. However, older calves kept indoor were characterised by better daily gains, feed intake and as a result, body weight. The outdoor system has positive effect on morbidity, especially in case of pneumonia and diarrhoea. During the experiment, only two calves were lost (mortality rate $-2.2 \%$ ).
\end{abstract}

Keywords: calves, housing system, individual pens (hutches), calves' rearing parameters, health

Abbreviations: IHG: indoor housing group, LSM: least square means, OHG: outdoor housing group, SE: standard error 


\section{Introduction}

Infectious diseases of calves, especially diarrheal and respiratory diseases, are associated with significant economic losses to the Polish dairy cattle industry. Their occurrence before 90 days affects their performance in later life and is associated with higher age at calving (Waltner-Toews et al. 1986).The mortality rate for new-born dairy calves (within $24 \mathrm{~h}$ after delivery) is approximately 2.5 to $9 \%$ and strongly depends upon may factor i. e.: breed, parity as well as environmental conditions (Nogalski \& Modras 2009). The occurrence of infectious diseases of the calf also affects human health safety through either direct contamination or pathogen transmission. To avoid mentioned hazards appropriate management practices should be involved in dairy calf rearing.

The successful management of artificially reared calves requires the provision of suitable housing conditions as well as reduction in environmental pathogens pressure.

According to Waltner-Toews et al. (1986) who conducted the survey in Canada, the farmlevel mortality rate per 6-month season (winter/summer) was $6 \%$. Peters (1986) who studied the effects of housing (indoor vs. outdoor), penning (individual vs. group), observed that that pneumonia was the most common disease symptom (48.3\%) with diarrhoea the second most common (14.1\%). Neither the type of pens nor the housing system affected the incidence of pneumonia; however, diarrhoea was most common in individually penned calves. Nevertheless, limitations of space, inadequate diet and social environment have been reported to impair the welfare of calves reared in intensive farm systems (Le Neindre 1993). According to Erley et al. (2004) the peak of death and cull losses of calves occurred during the 7th and 8th week of life. The key to success for the dairy calves rearing includes such parameters as nutrition with colostrum at a respective time, hygiene of milk and water, method of housing and type of materials for bedding (Berge et al. 2009). A bad health state of calves is often ascribed to »bad ventilation « what means, in practice, complex of environmental factors such as temperature, air flow, air humidity, pathogenic factors and concentration of gases (Turnbull 1980). Therefore, the conditions for management of hygiene, quality, functionality and microclimate of farm premises have a direct influence on feeling, health and, in consequence, productivity of animals (Szewczuk et al. 2011). To reduce the incidence of respiratory disease in dairy calves some producers have used outdoor hutches. Virtala et al. (1999) reported that housing calves in the presence of adult cattle was a risk factor for pneumonia, whereas housing mostly alone limited the incidents of respiratory tract diseases. One of the first studies (Kurtz 1961), comparing the rearing of calves in the building and outside i.e. in individual hutches, revealed that the calves kept outdoor had better body weight gains and lower mortality compared to the animals kept in the buildings. Andrighetto et al. (1999) observed a favourable effect of group housing on growth performance. However, Fisher et al. (1985) reported on lower daily gains and reduced feed efficiency of calves kept in narrow individual pens compared to animals kept in wider individual pens. Hill et al. (2007) noticed that natural ventilation of premises for calves at any weather conditions, especially in the winter period, had a positive effect on consumption of feed and growth rate of young calves. There are scarce studies concerning the housing system and its influence on parameters of calves rearing in Poland.

The aim of the present study was to compare two housing systems for calves: indoor - in group pens and outdoor - in individual hutches, outside the cow barn. 


\section{Material and methods}

The research material included 90 cow calves of Polish Holstein Friesian breed, Black-andWhite variety. The animals were classified at random into two groups, depending on the rearing system: in individual hutches (outdoor housing group [OHG], $\mathrm{n}=45$ ) and in group pens in calf house (indoor housing group [IHG], $n=45$ ) where they stayed since the 5th day until the end of the $3 \mathrm{rd}$ month of life. The body weight of the calves from the OHG and IHG on the 5th day of life was similar and amounted to 43.40 and $45 \mathrm{~kg}$, respectively. Individual hutches were made from wooden constructions with dimensions $0.9 \times 1.7 \mathrm{~m}$, with a hardened concrete runway with dimensions of $1.0 \times 1.3 \mathrm{~m}$. The hutches were installed in a series, at a distance of $0.5 \mathrm{~m}$ each; the calves could see and smell each other but could not touch themselves. Group pens in the building had dimensions of $3.0 \times 2.80 \mathrm{~m}$ and included five calves each. In both systems, the stock density was $1.6 \mathrm{~m}^{2}$ per animal. Change of bedding occurred every day, the use of straw was $2 \mathrm{~kg} / \mathrm{bed} /$ day.

The calves received colostrum until the 4th day of life (twice a day). Since the 5th day, they were fed (twice a day) milk replacer "Spezial Neu« (Josera GmbH, Kleinheubach, Germany), which contained $22 \%$ of crude protein, $19.5 \%$ of crude fat and $0.1 \%$ of fibre and since the 9th week of life milk replacer »Fe-Trank« (Josera GmbH, Kleinheubach, Germany) with the following composition: $23.5 \%$ crude protein, $12.5 \%$ crude fat and $3.5 \%$ of fibre. Colostrum and milk substitutes were administrated in special buckets, furnished with nippers for the IHG as well as for the OHG group. Since the 2 nd week of life concentrates were administered ad libitum (Table 1); since the 11th week meadow hay of good quality. The calves kept indoor had an unlimited access to water; the calves from hutches received water after feeding with the milk replacer twice a day.

Table 1

Composition of concentrate

\begin{tabular}{lr}
\hline Item & $\%$ \\
\hline Corn (whole grain) & 43.5 \\
Barley+Ground triticale & 31.6 \\
Soybean meal & 19.0 \\
Lacto Plus & 2.5 \\
Hefe-Krauter-Mineral & 2.5 \\
CO BIND A-Z & 0.5 \\
Salt & 0.1 \\
Pasture ground chalk & 0.3 \\
Total & 100.0 \\
\hline
\end{tabular}

During the growth and development calves were weighed on the 5th, 19th, 33rd, 47th, 61st, 75th, 85th, 90 th and 115 th day of life. On the ground of the obtained body weights, daily gains in one month, two and three months of rearing were calculated. Concentrates administered to the calves and the rejected (not consumed) feed were weighed; from the difference, the concentrate intake was calculated on every day of life and for every calf. In case of calves in the group, the mean feed consumption was calculated for each animal. The observation of 
disease incidence was carried out with consideration of diseases of the respiratory system and alimentary tract and cases of mechanical trauma.

Włodawa community, at the territory of which the studies were conducted, belongs to the Lubelskie voivodeship which is situated in the eastern part of Poland. Climatic conditions at the territory of Włodawa are somewhat cooler compared to the climate of Poland. The mean annual temperature is $7.3^{\circ} \mathrm{C}$ what is equal to the average for the country whereas the amplitude of temperatures is $22.2^{\circ} \mathrm{C}$ (average temperature of July is $18^{\circ} \mathrm{C}$ and of January $-4.2^{\circ} \mathrm{C}$ ). The average temperature of the warm half-a-year period (IV-X) is $13.2^{\circ} \mathrm{C}$ and this of the cold one is equal to $-1{ }^{\circ} \mathrm{C}$ up to $-3^{\circ} \mathrm{C}$. The discussed area is characterised, inter alia, by a longer summer time, lasting for 98 days and a longer winter period (up to 80 days) compared to the Central Poland.

The air temperature was measured every day during the whole period of the experiment in the calf house and outside the building - for hutches at 5.00 a.m., 12.00 and 5.00 p.m. using an alcohol thermometer. From this background the mean daily air temperature was calculated. In Table 2 the mean, the lowest and the highest values of the recorded air temperatures for each rearing system have been given.

Table 2

Mean, minimal and maximum values of air temperature for outdoor and indoor systems at 5.00, 12.00 and 17.00

\begin{tabular}{llccc}
\hline & & 5.00 & 12.00 & 17.00 \\
\hline \multirow{3}{*}{ Outdoor, ${ }^{\circ} \mathrm{C}$} & Mean & 2.17 & 11.12 & 9.46 \\
& Min & -28 & -16 & -22 \\
& Max & 19 & 40 & 33 \\
\hline \multirow{3}{*}{ Indoor, ${ }^{\circ} \mathrm{C}$} & Mean & 9.86 & 13.10 & 13.08 \\
& Min & 1 & 1 & 2 \\
& Max & 22 & 28 & 28 \\
\hline
\end{tabular}

All cow calves were wormed in the 3rd week of life using Biomectin (Tapazol Chemical Works Ltd., Beit Shemesh, Israel) $1 \%$.

The obtained results were statistically analysed, using two factor analysis of variance by the IBM SPSS Statistics 19 (SPSS Inc., Chicago, IL, USA). Body weight, daily gains, daily intake and orts were analysed with the general linear model. The model included fixed effects of the housing system, environmental temperature, time (week or month of experiment) and the housing $\times$ time interaction as well as housing $\times$ temperature interaction. The calf was included in the model as the random effect.

The impact of the birth season on the rearing effect of calves was also investigated. A detailed description of the methods and results is included in the article of Wójcik et al. (2012). The incidences of the disease distribution were analysed using the chi-square test.

\section{Results}

The body weights of calves on particular days of life depending on the management system are given in Table 3. Highly significant differences were recorded on the 85th day of life - the 
calves from the IHG were $5.36 \mathrm{~kg}$ heavier in comparison to the calves from the hutches. In consequence, the animals from the IHG had a $5 \mathrm{~kg}$ higher body weight on the 90th day of the experiment.

Table 3

Body weight of calves depending on rearing system, $\mathrm{kg}$

\begin{tabular}{|c|c|c|c|c|c|c|c|c|c|}
\hline \multirow{3}{*}{ Day of life } & \multicolumn{6}{|c|}{ Housing system } & & & \\
\hline & \multicolumn{3}{|c|}{ Outdoor } & \multicolumn{3}{|c|}{ Indoor } & \multicolumn{3}{|c|}{ Total mean } \\
\hline & $\mathrm{n}$ & LSM & SE & $\mathrm{n}$ & LSM & SE & $\mathrm{n}$ & LSM & SE \\
\hline 5 & 44 & 45.00 & 0.950 & 45 & 43.40 & 0.940 & 89 & 44.20 & 0.681 \\
\hline 19 & 44 & 48.94 & 1.033 & 45 & 47.71 & 1.022 & 89 & 48.33 & 0.741 \\
\hline 33 & 44 & 56.23 & 1.071 & 45 & 55.15 & 1.060 & 89 & 55.69 & 0.768 \\
\hline 47 & 44 & 64.30 & 1.211 & 45 & 63.80 & 1.198 & 89 & 64.05 & 0.868 \\
\hline 61 & 44 & 73.04 & 1.397 & 45 & 74.29 & 1.382 & 89 & 73.67 & 1.002 \\
\hline 75 & 44 & 82.61 & 1.631 & 45 & 86.25 & 1.613 & 89 & 84.43 & 1.169 \\
\hline 85 & 44 & $90.14^{\mathrm{A}}$ & 1.817 & 45 & $95.50^{A}$ & 1.797 & 89 & 92.82 & 1.303 \\
\hline 90 & 44 & 95.20 & 1.927 & 44 & 100.49 & 1.939 & 89 & 97.85 & 1.390 \\
\hline
\end{tabular}

Numerical values in the same line, marked with the same letter differ significantly $(P \leq 0.01)$.

Daily gains in the 1st month of life were almost identical (Table 4). Highly significant differences were found in the 2nd and 3rd month of life; the calves kept in the IHG system had quicker gains compared to the $\mathrm{OHG}$ calves (by $13.88 \%$ and $17.08 \%$, respectively).

Table 4

Average daily gains depending on housing system during the first three months of life, $\mathrm{g} / \mathrm{d}$

\begin{tabular}{|c|c|c|c|c|c|c|}
\hline \multirow{3}{*}{ Month } & \multicolumn{6}{|c|}{ Housing system } \\
\hline & \multicolumn{3}{|c|}{ Outdoor } & \multicolumn{3}{|c|}{ Indoor } \\
\hline & $\mathrm{n}$ & LSM & SE & $\mathrm{n}$ & LSM & SE \\
\hline 1 & 44 & 401.21 & 16.527 & 45 & 419.84 & 16.345 \\
\hline 2 & 44 & $600.20^{c}$ & 20.864 & 45 & $683.53^{c}$ & 20.635 \\
\hline 3 & 44 & $765.40^{D}$ & 26.654 & 44 & $896.14^{\mathrm{D}}$ & 26.810 \\
\hline
\end{tabular}

Numerical values in the same line, marked with the same letters differ significantly $(P \leq 0.01)$.

Differences between the IHG and OHG in respect of daily gains were caused by a higher starter feed intake (Figure 1). Feed intake differed highly significantly between the groups in the period up to the 9th week of life; calves from the OHG consumed less feed compared to IHG calves. After the 9th week of life, the increase in feed intake was recorded in both discussed groups and the mentioned trend was maintained until the end of the 3rd month of life. It was additionally observed that after termination of the experiment (14th and 15th week) the calves from the hutches which were transferred to the building and kept in the groups (five individuals in each pen), consumed significantly more feed than their contemporaries. It could result from the greater interest in feed via direct contact between the animals what was considerably limited earlier. 


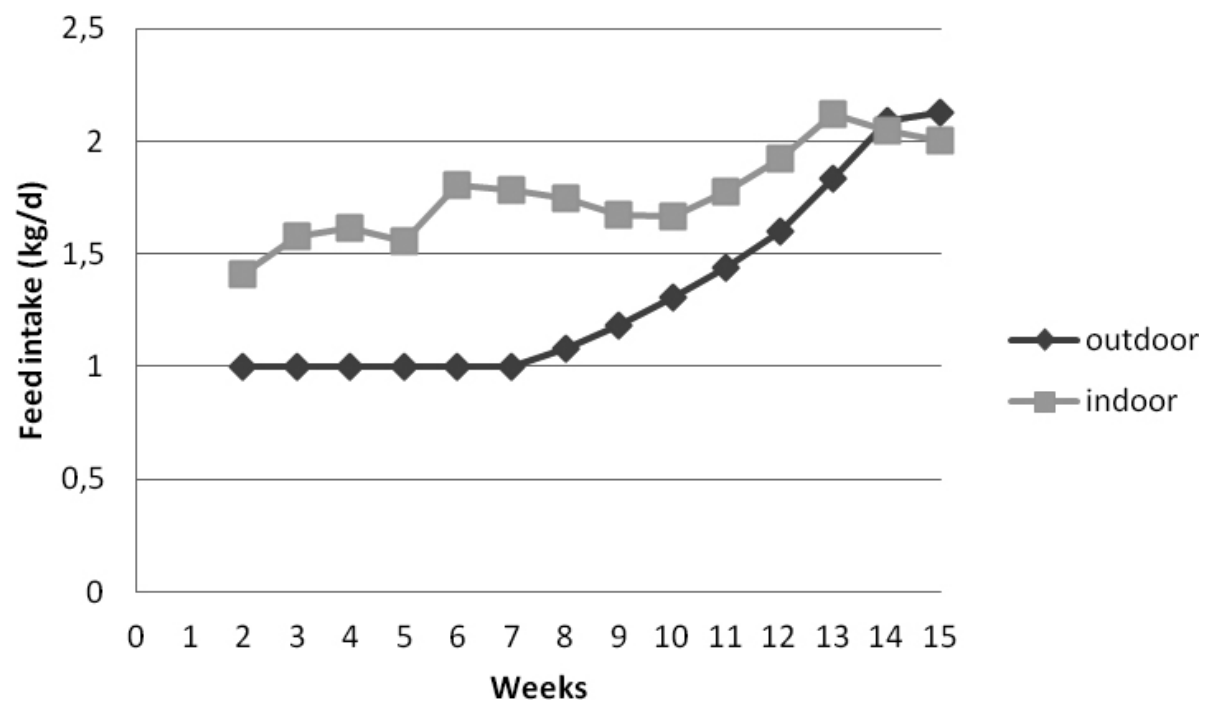

Figure 1

Feed intake $(\mathrm{kg} / \mathrm{d})$ depending on housing system

In the experiment, the rejected feed for each group was controlled (Figure 2). The quantity of the rejected feed affects negatively the economy of rearing the calves intended for replacement, increasing the costs of production. A considerably smaller quantity of the refused feed was recorded in the $\mathrm{OHG}$; after 13 weeks of the experiment a dramatic decline of the rejected feed was found in both discussed groups.

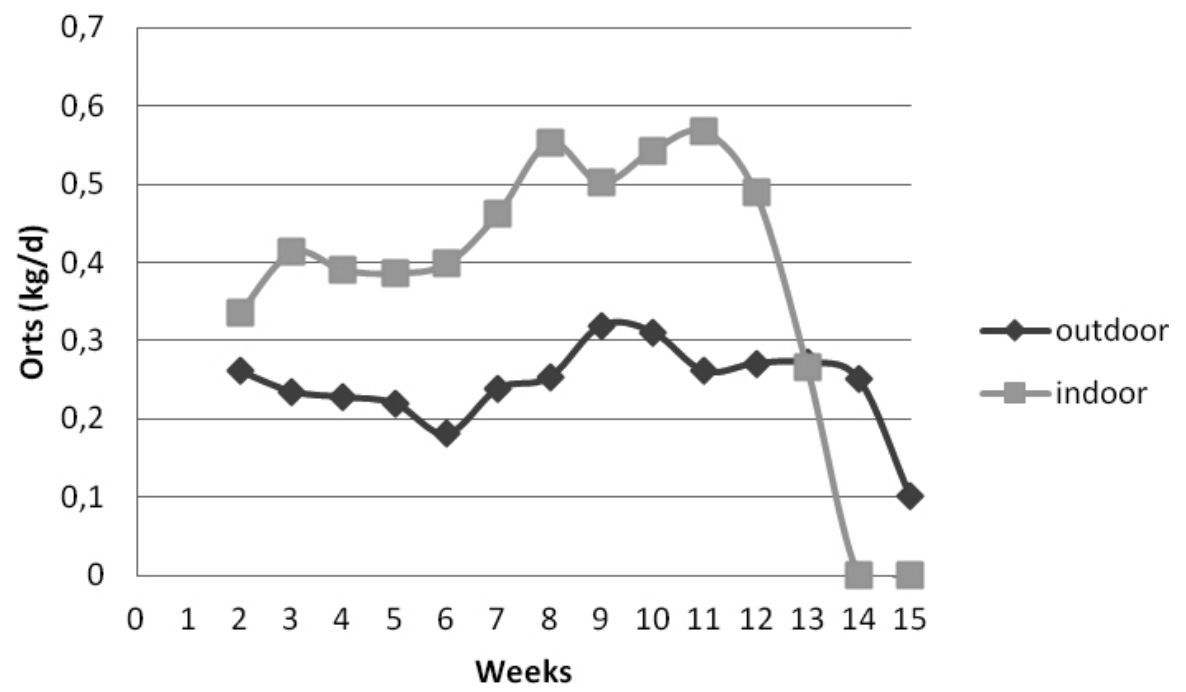

Figure 2

The refused feed in case of the examined animals, $\mathrm{kg} / \mathrm{d}$

The appetite of animals is greatly dependent on the temperature of their environment, therefore, the effect of the mean daily temperature and housing system on the mean daily 
gains of the calves was examined (Table 5). It was revealed that the interaction between the mentioned variables was highly significant. At a temperature below $0{ }^{\circ} \mathrm{C}$, the calves from the hutches revealed a growth rate on the level of $521.8 \mathrm{~g} /$ day; in the calf pen, a temperature below $0{ }^{\circ} \mathrm{C}$ was not recorded. Below the minimal temperature $\left(<8^{\circ} \mathrm{C}\right)$, the calves from the »cold rearing « showed $1.16 \%$ higher daily gains compared to the animals kept indoor. At the optimal temperature $\left(12-16^{\circ} \mathrm{C}\right)$ cow calves kept in calf pens had higher daily gains compared to the animals reared in the hutches; the difference was equal to $205.7 \mathrm{~g} / \mathrm{day}$. Above the optimal temperature, daily gains of the calves from the building were higher than those from individual hutches what was caused by better shadow and a smaller exhibition of the calves from the building to the sun. In both housing systems, it was observed that the animals had higher gains at temperatures lower than the optimal one what would confirm the thesis that together with the decline of temperature of the environment, the calves had more effective gain.

Table 5

Average daily gains of calves depending on the mean daily temperature and housing system during the 1st month of life

\begin{tabular}{lcccccc}
\hline $\begin{array}{l}\text { Mean temperature } \\
{ }^{\circ} \mathrm{C}\end{array}$ & $\mathrm{n}$ & $\mathrm{LSM}$ & $\mathrm{SE}$ & $\mathrm{n}$ & LSM & SE \\
\hline$<0$ & 29 & 521.8 & 29.85 & - & - & - \\
$0.1-8 . .0$ & 50 & 654.1 & 21.19 & 49 & 646.6 & 24.8 \\
$8 . .1-11 . .9$ & 17 & 522.8 & 38.50 & 31 & 666.3 & 28.3 \\
$12 . .0-16 . .0^{\circ} \mathrm{C}$ & 21 & 538.4 & 38.09 & 31 & 744.1 & 29.38 \\
$>16.1^{\circ} \mathrm{C}$ & 15 & 562.6 & 41.41 & 22 & 635.1 & 31.91 \\
\hline
\end{tabular}

Interaction of mean daily temperature and housing system on daily gains of the calves was highly significant $(P \leq 0.01)$

The observations concerning the health state are given in Table 6 . In the calves from the OHG, $11 \%$ less cases of alimentary tract diseases and $8.2 \%$ less cases of respiratory system diseases were recorded. The calves from the IHG were not only more susceptible to diarrhoea and pneumonia but also favourable for the incidence of mechanical trauma (in Table 5 being marked as »other «) which resulted in the occurrence of non-specific inflammations of mucous membranes of the oral cavity. Such cases were not recorded in the animals from the hutches. During the duration of the experiment, one calf from the IHG and one calf from the OHG died; index of mortality was equal to $2.2 \%$.

Table 6

Health of calves during the experiment

\begin{tabular}{llcccc}
\hline Group & & Diarrhea & Pneumonia & Others & Deaths \\
\hline \multirow{2}{*}{ Outdoor } & No. of cases & 3 & 15 & 0 & 1 \\
& $\%$ & 6.8 & 34 & 0 & $2 . .2$ \\
\multirow{3}{*}{ Indoor } & No. of cases & 8 & 19 & 4 & 1 \\
& $\%$ & $17 . .8$ & $42 . .2$ & $8 . .9$ & $2 . .2$ \\
\hline
\end{tabular}




\section{Discussion}

In Poland, the interest of the breeders in cold rearing of the calves outside the building increased during the recent years. The system of the calf housing has undoubtedly an effect on the results of rearing the animals and their health state, which are connected with their later productivity. Bad microclimate conditions in old farm buildings lead to considerable economic losses caused by higher morbidity and mortality of cow calves. The introduction of individual rearing of animals - outside the building - at least during the first month of life of the calves seems to be the optimal solution.

The results of the studies of Jorgenson et al. (1969) and of Hill et al. (2011) confirm that the calves kept in the IHG had quicker body gains compared to the calves from the OHG. Different results were presented by Phillips (2004), who observed lower body gains in the calves from group housing $(0.70 \mathrm{~kg} / \mathrm{d})$ in comparison to the calves from individual management system $(0.88 \mathrm{~kg} / \mathrm{d})$, similarly as Razzaque et al. (2009) and Murley \& Culvahouse (1958).

The own studies revealed that the calves kept in groups took more feed than the $\mathrm{OHG}$ animals what was confirmed by Jorgenson et al. (1969) and Hill et al. (2011). Phillips (2004) found that the calves kept individually spent more time on lying compared to the calves managed in groups, which may learn to take the feed at the mentioned time. Earley et al. (2004) did not find any differences between the calves from outdoor and indoor housing systems in spite of the fact that all animals were individually managed. After the 9 th week of life, the cow calves show a considerable increase in feed intake what is probably connected with the development of the rumen as the dimension of the rumen in calves is proportional to their body weight (Vazquez-Anon et al. 1993), hence, the trend of feed intake was maintained until the 3rd month of life.

The consumption of feed is greatly dependent on temperature, occurring in the calf house. The own studies revealed that cow calves reached better gains at lower temperatures e.g. in winter than in summer what was confirmed by other authors - Chester-Jones et al. (2008) cit. after Hill et al. (2011) and McKnight (1978). Ensuring the optimal temperature and the possibility of social contacts to the calves (management in the group) resulted in better gains. Above the optimal temperature daily gains of the calves from individual hutches were lower what was caused by worse shadowing and exhibition to the sun. Coleman et al. (1996) recorded that the calves staying in the shadow showed less breaths per minute in the contrary to the »non-shadowed « animals, what is an evidence of smaller thermal stress of the mentioned calves. In both housing systems it was observed that the animals had higher gains at temperatures lower than the optimal one compared to those which were higher than the optimal temperature; it would confirm the thesis that together with the decline of temperature, the calves had more effective gains.

The calves kept individually outside the building were characterised by a better health state what was also confirmed in the studies of Razzaque et al. (2009) and of Jorgenson et al. (1969). Rearing in the traditional calf house was favourable for dissemination of germs and the animals kept in the group were more endangered to health problems compared to individually managed animals. Callan \& Gary (2002) confirm that the incidence of enzootic pneumonia (Enzootic pneumonia) of calves is traditionally connected with a weak ventilation of calf houses. Disturbances of the respiratory system and diarrhoea are more popular among 
the calves being found in the traditional calf house compared to the animals reared in the external pens (Davis et al. 1954, Earley et al. 2004).

In the own studies, a very low index of mortality was achieved; it was identical for both groups, however Jorgenson et al. (1969) recorded a greater number of death cases in the indoor housing, similarly as Razzaque et al. (2009), who recorded a high index of mortality for the calves reared in the traditional calf house $(0.23 \%)$, in comparison to $0.017 \%$ for individual hutches.

\section{References}

Andrighetto I, Gottardo F, Andreoli D, Cozzi G (1999) Effect of type of housing on veal calf growth performance, behaviour and meat quality. Livest Prod Sci 57, 137-145

Berge ACB, Besser TE, More DA, Sischo WM (2009) Evaluation of the effects of oral colostrum supplementation during the first fourteen days on the health and performance of preweaned calves. J Dairy Sci 92, 286-295

Callan R J, Garry F B (2002) Biosecurity and bovine respiratory disease. Vet Clin North Am Food Anim Pract 18, 57-77

Chester-Jones H, Ziegler DM, Larson R, Ziegler B, Soderholm C, Hayes S, Linn JG, Raeth-Knight M, Golombeski G, Broadwater N (2008) Applied calf research from birth to six months. Proc. 2008 Four State Dairy Nutr Mgmt Conf, lowa State University, Dubuque, USA, 106

Coleman DA, Moss BR, McCaskey TA (1996) Supplemental Shade for Dairy Calves Reared in Commercial Calf Hutches in a Southern Climate. J Dairy Sci 79, 2038-2043

Davis LR, Autrey KM, Herlich H, Hawkins Jr GE (1954) Outdoor Individual Portable Pens Compared with Conventional Housing for Raising Dairy Calves. J Dairy Sci 37, 562-570

Earley B, Murray M, Farrell JA, Nolan M (2004) Rearing calves outdoors with and without calf jackets compared with indoor housing on calf health and live-weight performance. Ir J Agric Food Res 43, 59-67

Fisher LJ, Peterson GB, Jones SE, Shelford JA (1985) Two Housing Systems for Calves. J Dairy Sci 68, 368-373

Hill TM, Bateman II HG, Aldrich JM, Schlotterbeck RL (2007) Effects of Feeding Rate of Milk Replacers and Bedding Material for Calves in a Cold, Naturally Ventilated Nursery. Professional Animal Scientist 23, 656664

Hill TM, Bateman II HG, Aldrich JM, Schlotterbeck RL (2011) Comparisons of housing, bedding, and cooling options for dairy calves. J Dairy Sci 94, 2138-2146

Jorgenson LJ, Jorgensen NA, Schingoethe DJ, Owens MJ (1969) Indoor versus Outdoor Calf Rearing at Three Weaning Ages. J Dairy Sci 53, 813-816

Kurtz E (1961) Raising dairy herd replacements. South Dakota State Coll Coop Ext Serv FS, 67

Le Neindre P (1993) Evaluating housing systems for veal calves. J Anim Sci 71, 1345-1354

McKnight DR (1978) Performance of newborn dairy calves in hutch housing. Can J Anim Sci 58, 517-520

Murley WR, Culvahouse EW (1958) Open Shed and Portable Pens versus Conventional Housing for Young Dairy Calves. J Dairy Sci 41, 977-981

Nogalski Z, Mordas W (2009) [Perinatal calf mortality in dairy cattle herds in north-eastern Poland]. Med Wet 65, 571-574 [in Polish]

Peters AR (1986) Some husbandry factors affecting mortality and morbidity on a calf-rearing unit. Vet Rec $119,355-357$

Phillips CJC (2004) The Effects of Forage Provision and Group Size on the Behavior of Calves. J Dairy Sci 87, 1380-1388

Razzaque MA, Abbas S, Al-Mutawa T, Bedair M (2009) Performance of pre-weaned female calves confined in housing and open environment hutches in Kuwait. Pak Vet J 29, 1-4 
Szewczuk M, Bogacka A, Czerniakowska- Piątkowska E (2011) Effect of calving season on the course of parturition and rearing results of polish Holstein- Friesian calves. Acta Sci Pol Zootec 10, 77-88

Turnbull JE (1980) Housing and Environment for Dairy Calves. Can Vet J 21, 85-90

Waltner-Toews D, Martin SW, Meek AH, McMillan I (1986) Dairy calf management, morbidity and mortality in Ontario Holstein herds. I. The data. Prev Vet Med 4, 103-124

Wójcik A, Nałęcz-Tarwacka T, Gołębiewski M (2012) Effect of hausing system and season of birth on the calves rearing results. Annals of Warsaw University of Life Sciences - SGGW, Animal Science 51, 139-146

Vazquez-Anon M, Heinrichs AJ, Aldrich JM, Varga GA (1993) Postweaning Age Effects on Rumen Fermentation End-Products and Digesta Kinetics in Calves Weaned at 5 Weeks of Age. J Dairy Sci 76, 2742-2748

Virtala A-MK, Gröhn YT, Mechor GD, Erb HN (1999) The effect of maternally derived immunoglobulin G on the risk of respiratory disease in heifers during the first 3 months of life. Prev Vet Med 39, 25-37 